\title{
A systematic review of laparoscopic total gastrectomy for gastric cancer
}

\author{
Chikara Kunisaki $\cdot$ Hirochika Makino $\cdot$ Ryo Takagawa $\cdot$ \\ Jun Kimura $\cdot$ Mitsuyoshi Ota $\cdot$ Yasushi Ichikawa $\cdot$ Takashi Kosaka \\ Hirotoshi Akiyama $\cdot$ Itaru Endo
}

Received: 21 December 2014/ Accepted: 25 January 2015/Published online: 11 February 2015

(C) The International Gastric Cancer Association and The Japanese Gastric Cancer Association 2015

\begin{abstract}
Background Laparoscopic total gastrectomy (LTG) has been performed since 1999. Although surgical outcomes have been reported from Japan, Korea, China, and many Western countries, the effectiveness of this technique has not been conclusively established. This study therefore aimed to review the literature systematically.

Methods Our search of the research literature identified 150 studies, which were mostly retrospective and from single institutions.

Results There has recently been a remarkable increase in the number of studies from Korea, and the number of patients included in studies has increased since 2009. In most studies, the surgical procedures were longer, blood loss was reduced, and the number of retrieved lymph nodes was the same in the LTG group as in the open total gastrectomy group. The incidence of postoperative complications and that of inflammation during postoperative recovery were the same in these two groups.

Conclusions During LTG, the method used for esophagojejunostomy is important for surgical reliability and to reduce postoperative complications. There has been
\end{abstract}

C. Kunisaki $(\bowtie) \cdot$ H. Makino $\cdot$ R. Takagawa $\cdot$ J. Kimura ·

M. Ota

Department of Surgery, Gastroenterological Center, Yokohama

City University, 4-57, Urafune-cho, Minami-ku,

Yokohama 232-0024, Japan

e-mail: s0714@med.yokohama-cu.ac.jp

Y. Ichikawa

Department of Clinical Oncology, Graduate School of Medicine,

Yokohama City University, Yokohama, Japan

T. Kosaka $\cdot$ H. Akiyama $\cdot$ I. Endo

Department of Gastroenterological Surgery, Graduate School of

Medicine, Yokohama City University, Yokohama, Japan rapid development of new techniques from the level of esophagojejunostomy through a small skin incision to the high level of intracorporeal esophagojejunostomy using various techniques. A nationwide prospective phase II study is urgently needed to establish the value of LTG.

Keywords Laparoscopic total gastrectomy · Gastric cancer $\cdot$ Systematic review

\section{Introduction}

Gastric cancer is the fourth most prevalent cancer and the second commonest cause of cancer-related deaths worldwide [1]. Surgically curative gastrectomy is the mainstay of treatment for early and advanced gastric cancer. In Japan and Korea, laparoscopic gastrectomy has become the prevalent surgical technique for treatment of early gastric cancer [2-5] and for treatment of a subset of advanced gastric cancers [6-9]. The first report of laparoscopy-assisted distal gastrectomy (LADG) for gastric cancer was by a Japanese surgeon [10]. Since then, many researchers have published studies reporting appropriate techniques, shortterm and long-term outcomes, and quality-of-life measures for patients after LADG [11-16]. Moreover, a nationwide randomized controlled study in Korea is being conducted, with satisfactory interim results reported, and data collection is ongoing [17].

Recently, laparoscopic total gastrectomy (LTG), also known as laparoscopy-assisted total gastrectomy and which is a more complex surgical procedure, has been more frequently used, and its outcomes are beginning to be reported [18-21]. Moreover, new techniques for LTG, in which intracorporeal esophagojejunostomy can be performed completely laparoscopically, have been 

concerning laparoscopic total gastrectomy by year according to the country of origin
Fig. 1 Number of publications

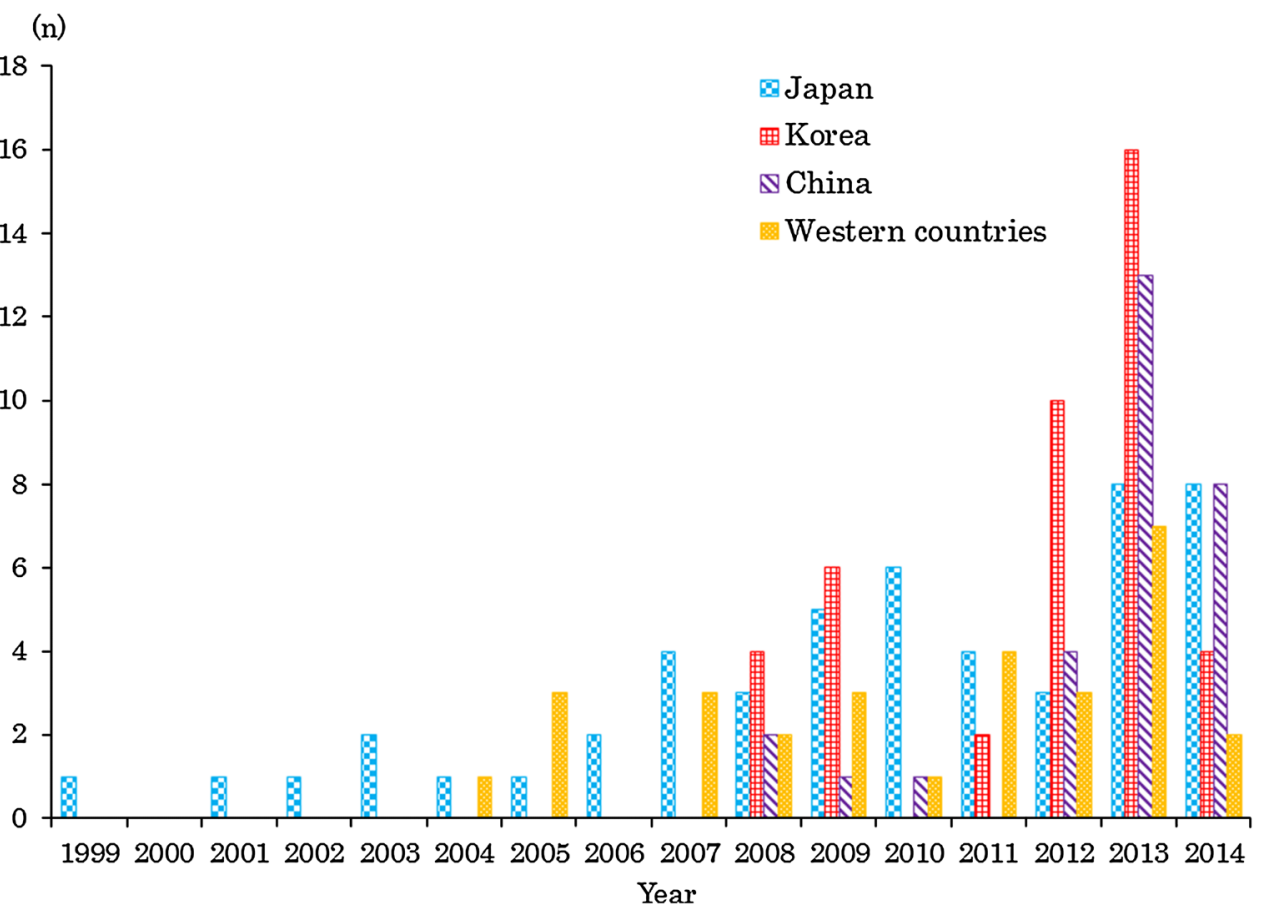

developed in some high-volume centers, and some shortterm outcomes have been reported [22-24]. However, the potential surgical benefits of LTG have not yet been assessed in a well-designed nationwide phase II study or a randomized controlled study. Before one embarks on a nationwide study, it is important to review systematically the current state of knowledge concerning these novel surgical procedures. We have therefore conducted this systematic review to clarify the advantages of LTG for gastric cancer, irrespective of cancer stage, with respect to intraoperative factors, short-term outcomes, and oncological long-term outcomes.

\section{Methods}

\section{Article selection}

English language articles relevant to LTG for gastric cancer were identified in PubMed (http://www.ncbi.nlm.nih. gov/pubmed) by searching for the terms "gastric cancer" and "laparoscopic total gastrectomy" in articles published up to the end of October 2014. The inclusion criteria for these studies were meta-analyses, prospective cohort studies or retrospective studies assessing surgical outcomes of LTG, and comparative studies of LTG and open total gastrectomy (OTG), but case reports were excluded. The end points included in our study were intraoperative factors (operation time, blood loss, and extent of lymph node dissection), postoperative morbidities (anastomotic leakage, anastomotic stricture, pancreatic fistula, surgical site infections, and pneumonia), postoperative recovery (postoperative inflammatory response, and length of hospital stay), mortality, and long-term oncological outcomes. The initial search identified 552 reports in the database, of which 150 reports were actually related to LTG. We reviewed these 150 reports in this study.

\section{Results}

Annual publications

In a 1997 study, a questionnaire was sent to 16 surgeons worldwide and data were collected on 118 laparoscopic gastrectomies [25]. Although ten LTGs were included in this study, this was not regarded as the first report, because of its small sample size and because the results were collected by a questionnaire. Since LTG was first reported as a technical note in 1999 [26], some further studies have been reported [18-24]. Of these, the highest number of publications has been from Japan $(n=50)$, followed by Korea ( $n=42$; see Fig. 1). However, in the last 5 years more of the studies published have come from Korea. An equal number of studies $(n=29)$ have been reported from China and Western countries.

A total of 134 retrospective studies included 37 comparative studies of LTG and OTG, and the remaining 97 studies focused on therapeutic outcomes for LTG within a single institute (see Fig. 2a). In addition, eight meta-analyses and eight retrospective, multi-institutional studies were identified. There were no prospective randomized 
Fig. 2 Number of publications concerning laparoscopic total gastrectomy by year according to $\mathbf{a}$ the study design and $\mathbf{b}$ the size of the study groups $\mathbf{a}$

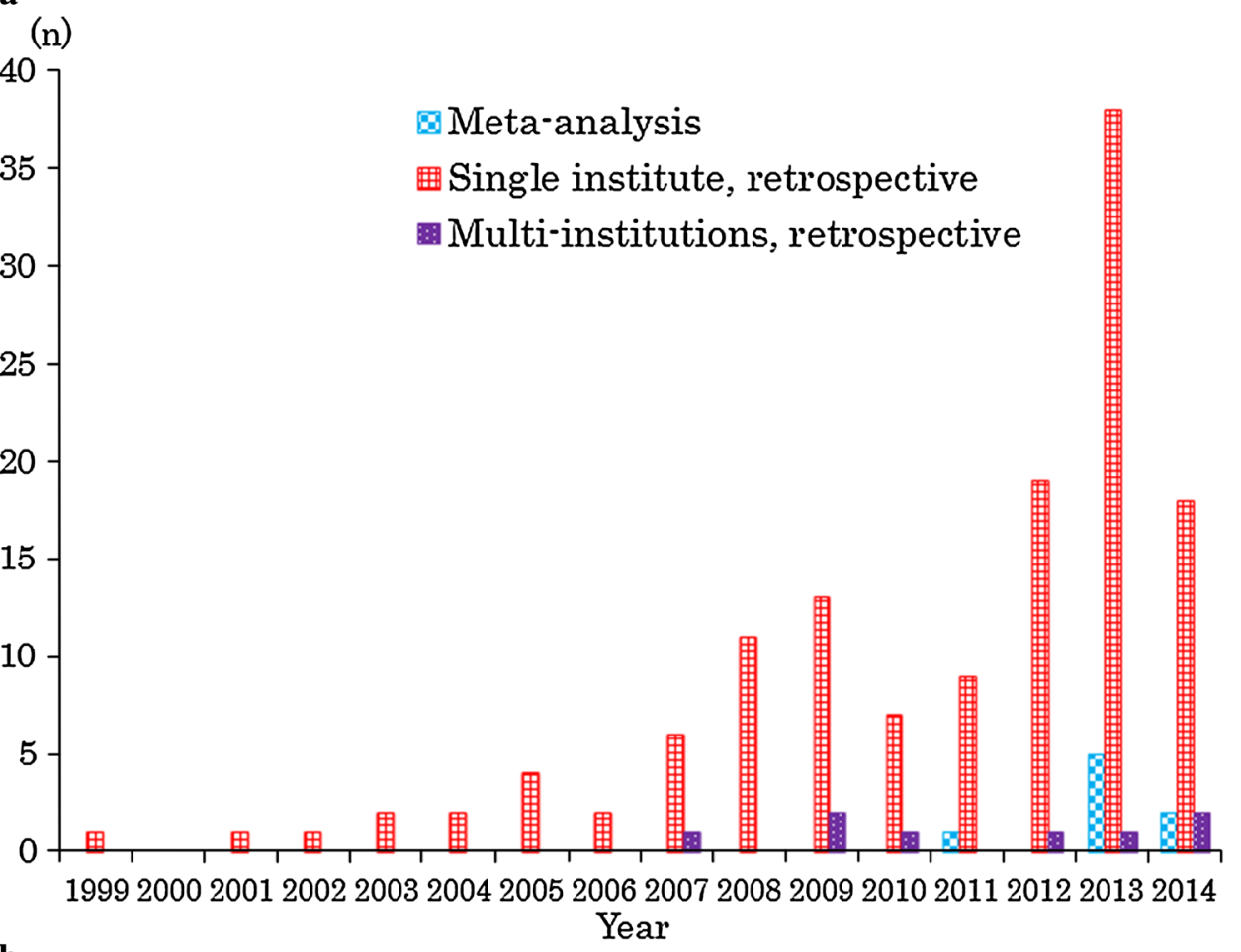

b

(n)

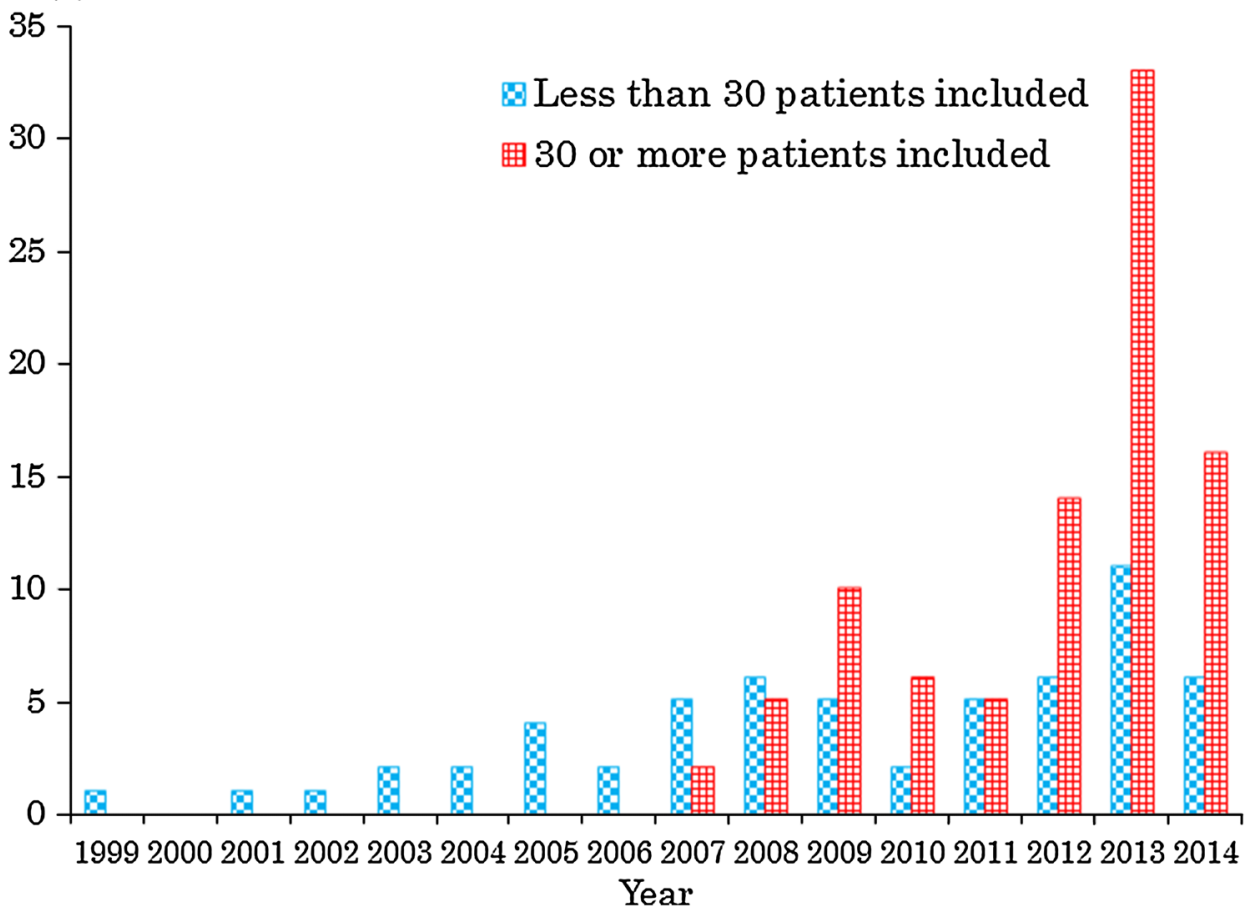

studies concerning LTG that included a significant number of patients. About $60 \%$ of the studies we identified included 30 or more patients, although there were no studies including 30 or more patients until 2007 (Fig. 2b). Compared with the number of studies concerning LADG, the number of reports about LTG was small.
Reconstruction methods after laparoscopic total gastrectomy

Various methods for performing esophagojejunostomies have been developed and established. Table 1 summarizes the reports that have evaluated the short-term surgical 


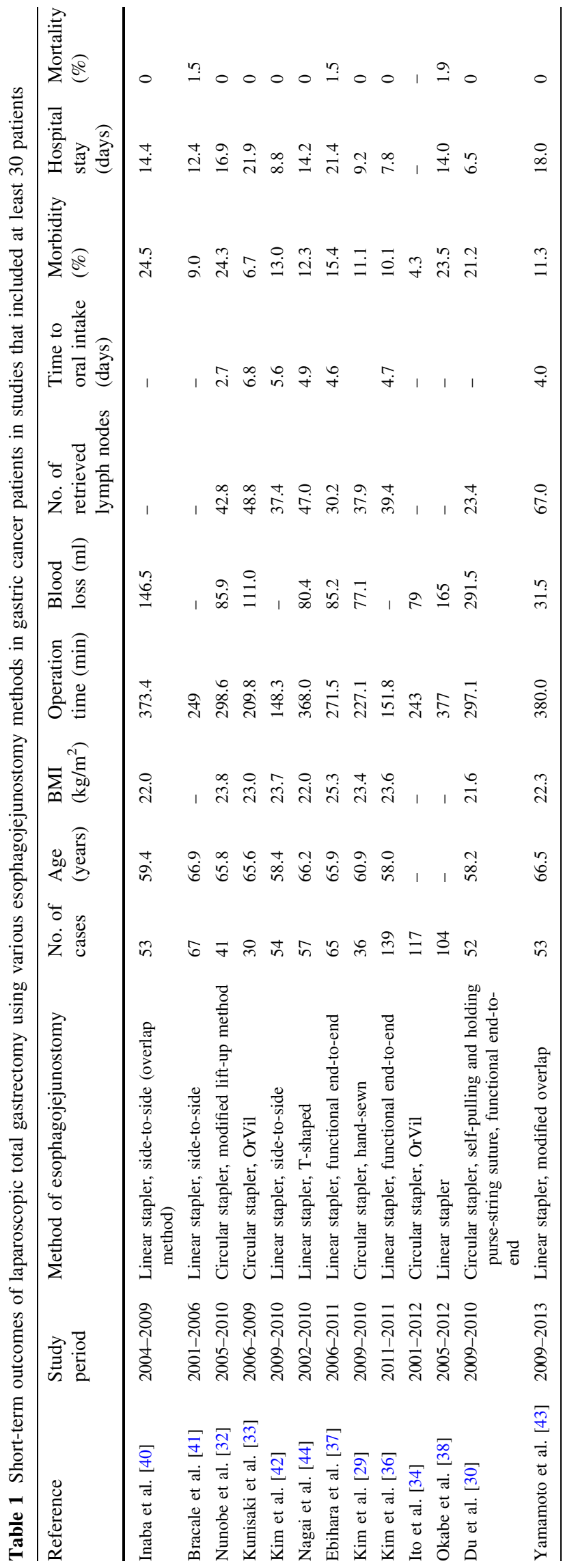

outcomes of different esophagojejunostomy methods after LTG, and which included at least 30 patients. In these 13 studies, esophagojejunostomies were performed intracorporeally.

Initially, esophagojejunostomy was performed with a circular stapler through a $10-\mathrm{cm}$ skin incision, using an anvil head inserted into the esophagus after a purse-string suture had been hand-sewn on the esophageal stump [27, 28]. However, a detailed view of the surgical site could not be achieved using this technique. It was therefore difficult to create an esophagojejunostomy at a deep site in the abdominal cavity, particularly in a male with significant visceral fat. Therefore, this technique was not acceptable to most gastric surgeons, and is no longer used.

The next development was the creation of an intracorporeal esophagojejunostomy using a circular stapler, whose use has become prevalent in many institutions since its introduction. Many surgeons had already been using a circular stapler to perform esophagojejunostomies for OTG and were already familiar with the difficulties and pitfalls of this method. However, laparoscopy-assisted or laparoscopic esophagojejunostomy cannot be performed in the same way as open esophagojejunostomy. A variety of techniques have been used for anvil insertion for a circular stapled esophagojejunostomy: laparoscopic hand-sewn purse-string sutures followed by intracorporeal insertion of the anvil [29, 30], a novel purse-string instrument [EndoPSI(II)] [31], insertion of an anvil through a small incision in the abdominal esophagus before dissection of the stomach and before the central rod is pulled out through the proximal esophagus followed by transection of the esophagus with a linear stapler [32], and an orally inserted anvil $\left(\mathrm{OrVil}^{\mathrm{TM}}\right)$ system. The OrVil ${ }^{\mathrm{TM}}$ tube with its connection to the anvil head is introduced transorally and is extracted intracorporeally from the esophageal stump, and finally the central rod is removed from the connection tube $[33,34]$. When the anvil head is being inserted into the esophagus, it is essential to stretch the patient's neck backward and gently pull the connecting tube until the anvil head reaches the esophageal stump. In our experience, the best method for forming the anastomosis is the hemidouble technique with the axis of the central rod and the shaft kept straight.

Two types of esophagojejunostomy have been reported using linear staplers, a functional end-to-end anastomosis [35-38] and a side-to-side anastomosis (or the overlap method) [39-43]. The functional end-to-end procedure is performed by inserting the linear stapler into the esophagus thorough a small hole on the left side of the esophageal stump and simultaneously lifting the jejunum to insert the stapler through a small hole on the opposite side of the jejunum mesenterium. The entry holes are closed using the linear stapler, usually one at a time. By contrast, the 
overlap method is performed by making holes on the left side of the esophageal stump and 6-7 $\mathrm{cm}$ from the jejunal stump. After stapling, the entry hole is closed using handsewn sutures. In both techniques it is essential that the linear stapler is inserted into the true esophageal lumen, so, to avoid insertion into the "pseudolumen", use of a nasogastric tube and a full-thickness stay suture on the esophagus were reported to be useful. A modified esophagojejunostomy has also been reported, and showed that an inverted-T-shaped anastomosis allowed the creation of an intracorporeal esophagojejunostomy without dissection around the abdominal esophagus and the lower mediastinum [44].

\section{Intraoperative factors}

Table 2 lists studies that compared the surgical outcomes of LTG and OTG in patients with gastric cancer, and which included at least 30 patients in each group. In many of these comparative studies, longer operation times, less blood loss, and equal numbers of dissected lymph nodes were observed in the LTG group compared with the OTG group [45-47]. Obviously, these outcomes will have been dependent on the extent of lymph node dissection, whether multiple organ resections were performed, and the skill of the surgeons in each study. Moreover, several meta-analyses showed equivalent outcomes for the two surgical procedures [48-50].

\section{Postoperative complications}

The incidence of postoperative complications in the LTG group ranged between 10 and $40 \%$ [18, 22]. Many studies reported that there were no significant differences in the incidence of complications between the LTG and OTG groups [45-47, 51]. Among anastomosis-related complications in the LTG group, leakage at the site of esophagojejunostomy was observed in $0.9-8.5 \%$ of patients, leakage at the duodenal stump was seen in $1.0-3.4 \%$ of patients, stricture at the site of esophagojejunostomy was seen in $0-9.0 \%$ of patients, intraluminal bleeding was seen in $0-7.6 \%$ of patients, and ileus or stasis was seen in 0-3.3\% of patients [19, 23]. By contrast, one study showed a high incidence of anastomosis-related complications in the LTG group [52].

Pancreatic fistula is another important complication to be considered when performing LTG [20, 24]. The incidence of pancreatic fistula did not differ between the LTG and OTG groups.

With respect to nonsurgical complications, pneumonia and infections at surgical sites occurred with the same frequency in the two groups. After LTG when splenectomy was also performed for complete D2 lymph node

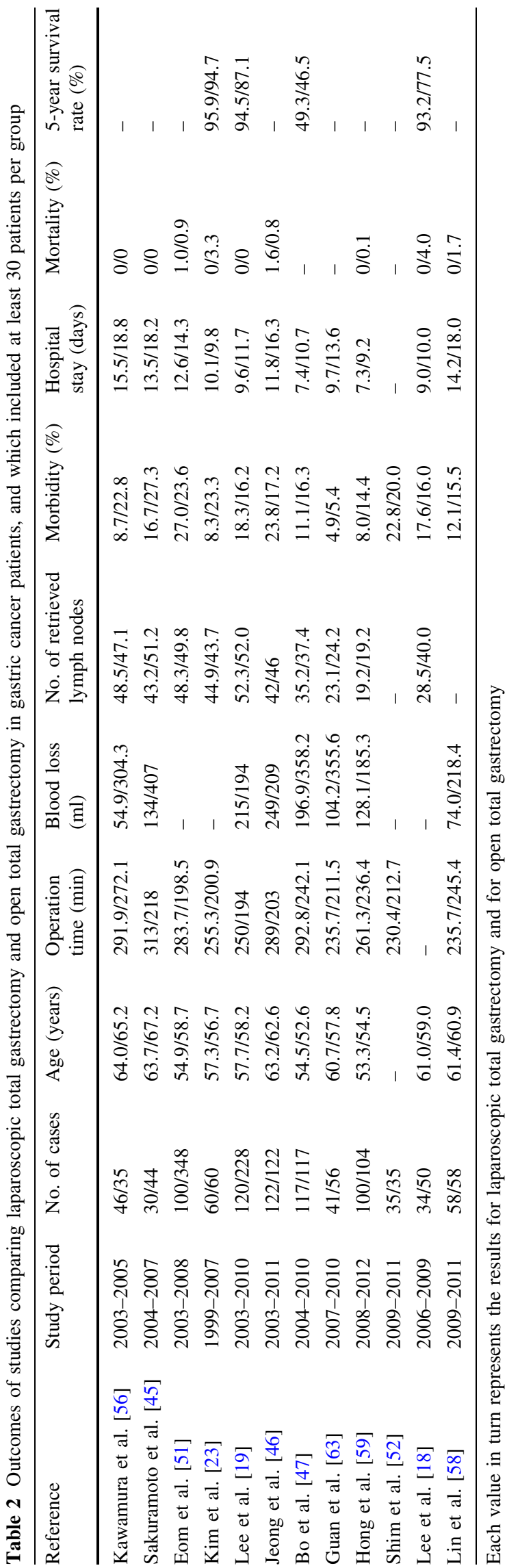


dissection, a higher incidence of postoperative complications occurred, equivalent to the incidence seen for OTGs $[53,54]$.

\section{Postoperative recovery}

In a few studies that assessed postoperative inflammation, C-reactive protein levels and white blood cell counts were found to be significantly reduced during the early postoperative phase in the LTG group compared with the OTG group. However, these were retrospective studies with small numbers of patients [55, 56]. However, another retrospective, comparative study found that the peak values of the C-reactive protein level and the white blood cell count did not differ between the LTG and OTG groups [11]. These indicators of inflammation varied with the extent of lymph node dissection, whether other organs were resected at the same time, the length of surgery, the volume of blood lost, and the incidence of postoperative complications.

Many studies have shown that the time to the first flatus, the time to the start of oral feeding, and the length of postoperative hospital stay were shorter in the LTG group than in the OTG group $[57,58]$. Moreover, one study reported a high quality of life in the LTG group [59]. However, the clinical paths in each study were different in different institutions, and also may have changed over time. It is therefore difficult to assess the course of postoperative recovery in retrospective studies. In most studies, mortality was low and acceptable, with no significant differences between different patient groups [18-24].

\section{Long-term survival}

Some studies compared long-term survival between the LTG and OTG groups [60, 61], and reported that they were similar in the two groups. However, the number of patients in these studies was small, and the results were not adjusted for cancer stage.

\section{Discussion}

Although we have been able to review over 100 publications concerning retrospective studies of LTG, the complexity and difficulty of the techniques required for this surgery may to a great extent explain why there are, as yet, no prospective studies concerning LTG. There is a need for a well-designed phase II study of LTG soon. Reviewing the current techniques in use for LTG and the state of knowledge about outcomes is important for the design of future studies.

We have reviewed the reconstructive techniques that have been used for esophagojejunostomy during LTG and have identified four techniques with their various advantages and disadvantages. Intracorporeal, hand-sewn, pursestring sutures are complex to perform and skills are needed which require a fairly long surgical learning curve to acquire. Use of the Endo-PSI(II) needs some fine manipulation to tie knots. In addition, forming anastomoses using the $\mathrm{OrVil}^{\mathrm{TM}}$ has some disadvantages. In spite of the requirement for precise manipulations mentioned above, the incidence of anastomotic leakage and the incidence of stenosis were relatively high compared with results seen with use of the other devices [62], so improvements to this device should be considered. It may be difficult to arrive at one uniform method for performing intracorporeal esophagojejunostomy using a circular stapler. Alternatively, surgeons may need to practice their skills using their favorite technique, so that this procedure can be performed reliably.

The reports concerning the creation of intracorporeal esophagojejunostomies using a linear stapler have been increasing in number and becoming prevalent, and they suggest that these techniques may be safe and reliable. However, the surgeon should be experienced and should use these techniques only after having performed a sufficient number of simpler laparoscopic gastrectomies.

Inevitably, more complex surgical manipulations lengthen the time an operation takes and may affect other intraoperative factors. More precise manipulation with more advanced devices may help to reduce blood loss, despite the extended time in surgery. Experienced laparoscopic surgeons are able to dissect appropriate lymph nodes to a sufficient extent, and consequently, reports have shown that the number of lymph nodes retrieved was not significantly different between the LTG and OTG groups. At this stage, we therefore suggest it is reasonable to recommend LTG for early gastric cancer, where more complex surgery requiring the resection of other organs is not required. We imagine that at present this complex surgery has been performed by experienced laparoscopic gastric surgeons, who had already had sufficient experience of LADG. Nevertheless, the short-term and long-term outcomes of LTG in patients with early-stage gastric cancer have been satisfactory, as reported in retrospective studies $[60,63]$, and justify use of this technique in early gastric cancer. However, the outcomes of LTG in patients with advanced gastric cancer have not yet been adequately studied [6]. The presence of a large, serosal exposed tumor, a requirement for extended lymph node dissection or a combined resection, and treatment with neoadjuvant chemotherapy can increase the difficulty of intraoperative manipulations and subsequently the risk of postoperative complications. Therefore, the feasibility of LTG should be further investigated in patients with early gastric cancer, before the technique is applied to more advanced stage cancer. In addition, it is difficult to compare long-term 
survival and to prove noninteriority of the laparoscopic approach between the LTG and OTG groups in patients with early gastric cancer owing to the paucity of cancerrelated death in this population. As it is not practical to obtain a sufficient sample size to give meaningful results in a randomized controlled trial, a prospective phase II study to evaluate the safety and feasibility of the laparoscopic approach for LTG could be sufficient.

Although current surgical procedures for LTG have not yet been widely established and standardized, reports have appeared concerning the application of more advanced techniques, such as robotic total gastrectomy [64, 65] and reduced-port LTG [66, 67]. Robotic gastrectomy has been reported to provide manipulations as reliable as those provided by LTG. By contrast, reduced-port LTG has been reported to be best performed by an experienced laparoscopic gastric surgeon. The significance of these techniques for gastric cancer treatment will require further evaluation.

In conclusion, LTG for gastric cancer should be performed by an experienced laparoscopic gastric surgeon, who has sufficient experience of more basic laparoscopic gastrectomies. The advantages and disadvantages of this technique should be verified in a nationwide prospective phase II study.

\section{References}

1. Ferlay J, Soerjomataram I, Dikshit R, Eser S, Mathers C, Rebelo $\mathrm{M}$, et al. Cancer incidence and mortality worldwide: sources, methods and major patterns in GLOBOCAN 2012. Int J Cancer. 2014. doi:10.1002/ijc.29210.

2. Misawa K, Fujiwara M, Ando M, Ito S, Mochizuki Y, Ito Y, et al. Long-term quality of life after laparoscopic distal gastrectomy for early gastric cancer: results of a prospective multi-institutional comparative trial. Gastric Cancer. 2014. doi:10.1007/s10120014-0374-y.

3. Takiguchi S, Fujiwara Y, Yamasaki M, Miyata H, Nakajima K, Sekimoto M, et al. Laparoscopy-assisted distal gastrectomy versus open distal gastrectomy. A prospective randomized singleblind study. World J Surg. 2013;37:2379-86.

4. Sakuramoto S, Yamashita K, Kikuchi S, Futawatari N, Katada N, Watanabe M, et al. Laparoscopy versus open distal gastrectomy by expert surgeons for early gastric cancer in Japanese patients: short-term clinical outcomes of a randomized clinical trial. 2013;27:1695-705.

5. Kim YW, Yoon HM, Yun YH, Nam BH, Eom BW, Baik YH, et al. Long-term outcomes of laparoscopy-assisted distal gastrectomy for early gastric cancer: result of a randomized controlled trial (COACT 0301). Surg Endosc. 2013;27:4267-76.

6. Park DJ, Han SU, Hyung WJ, Kim MC, Kim W, Ryu SY, et al. Long-term outcomes after laparoscopy-assisted gastrectomy for advanced gastric cancer: a large-scale multicenter retrospective study. Surg Endosc. 2012;26:1548-53.

7. Gordon AC, Kojima K, Inokuchi M, Kato K, Sugihara K. Longterm comparison of laparoscopy-assisted distal gastrectomy and open distal gastrectomy in advanced gastric cancer. Surg Endosc. 2013;27:462-70.
8. Huang JL, Wei HB, Zheng ZH, Wei B, Chen TF, Huang Y, et al. Laparoscopy-assisted D2 radical distal gastrectomy for advanced gastric cancer. Dig Surg. 2010;27:291-6.

9. Zhao Y, Yu P, Hao Y, Qian F, Tang B, Shi Y, et al. Comparison of outcomes for laparoscopically assisted and open radical distal gastrectomy with lymphadenectomy for advanced gastric cancer. Surg Endosc. 2011;25:2960-6.

10. Kitano S, Iso Y, Moriyama M, Sugimachi K. Laparoscopy-assisted Billroth I gastrectomy. Surg Laparosc Endosc. 1994;4:146-8.

11. Kunisaki C, Makino H, Kosaka T, Oshima T, Fujii S, Takagawa $\mathrm{R}$, et al. Surgical outcomes of laparoscopy-assisted gastrectomy versus open gastrectomy for gastric cancer: a case-control study. Surg Endosc. 2012;26:804-10.

12. Fukunaga T, Hiki N, Kubota T, Nunobe S, Tokunaga M, Nohara $\mathrm{K}$, et al. Oncologic outcomes of laparoscopy-assisted distal gastrectomy for gastric cancer. Ann Surg Oncol. 2013;20:2676-82.

13. Kim DG, Choi YY, An JY, Kwon IG, Cho I, Kim YM, et al. Comparing the short-term outcomes of totally intracorporeal gastroduodenostomy with extracorporeal gastroduodenostomy after laparoscopic distal gastrectomy for gastric cancer: a single surgeon's experience and a rapid systematic review with metaanalysis. Surg Endosc. 2013;27:3153-61.

14. Kim HH, Han SU, Kim MC, Hyung WJ, Kim W, Lee HJ, et al. Prospective randomized controlled trial (phase III) to comparing laparoscopic distal gastrectomy with open distal gastrectomy for gastric adenocarcinoma (KLASS 01). J Korean Surg Soc. 2013;84:123-30.

15. Zhao XF, Jeong O, Jung MR, Ryu SY, Park YK. A propensity score-matched case-control comparative study of laparoscopic and open extended (D2) lymph node dissection for distal gastric carcinoma. Surg Endosc. 2013;27:2792-800.

16. Kitano S, Shiraishi N, Uyama I, Sugihara K, Tanigawa N, Japanese Laparoscopic Surgery Study Group. A multicenter study on oncologic outcome of laparoscopic gastrectomy for early cancer in Japan. Ann Surg. 2007;245:68-72.

17. Kim HH, Hyung WJ, Cho GS, Kim MC, Han SU, Kim W, et al. Morbidity and mortality of laparoscopic gastrectomy versus open gastrectomy for gastric cancer: an interim report -a phase III multicenter, prospective, randomized trial (KLASS trial). Ann Surg. 2010;251:417-20.

18. Lee SR, Kim HO, Son BH, Shin JH, Yoo CH. Laparoscopicassisted total gastrectomy versus open total gastrectomy for upper and middle gastric cancer in short-term and long-term outcomes. Surg Laparosc Endosc Percutan Tech. 2014;24:277-82.

19. Lee, Lee JH, Park DJ, Lee HJ, Kim HH, Yang HK. Comparison of short- and long-term outcomes of laparoscopic-assisted total gastrectomy and open total gastrectomy in gastric cancer patients. Surg Endosc. 2013;27:2598-605.

20. Wada N, Kurokawa Y, Takiguchi S, Takahashi T, Yamasaki M, Miyata $\mathrm{H}$, et al. Feasibility of laparoscopy-assisted total gastrectomy in patients with clinical stage I gastric cancer. Gastric Cancer. 2014;17:137-40.

21. Ahn SH, Lee JH, Park DJ, Kim HH. Comparative study of clinical outcomes between laparoscopy-assisted proximal gastrectomy (LAPG) and laparoscopy-assisted total gastrectomy (LATG) for proximal gastric cancer. Gastric Cancer. 2013;16:282-9.

22. Tsunoda S, Okabe H, Obama K, Tanaka E, Hisamori S, Kinjo Y, et al. Short-term outcomes of totally laparoscopic total gastrectomy: experience with the first consecutive 112 cases. World J Surg. 2014;38:2662-7.

23. Kim KH, Kim YM, Kim MC, Jung GJ. Is laparoscopy-assisted total gastrectomy feasible for the treatment of gastric cancer? A case-matched study. Dig Surg. 2013;30:348-54. 
24. Nakata K, Nagai E, Ohuchida K, Shimizu S, Tanaka M. Technical feasibility of laparoscopic total gastrectomy with splenectomy for gastric cancer: clinical short-term and long-term outcomes. Surg Endosc. 2014 doi:10.1007/s00464-014-3870-6.

25. Goh PM, Alponat A, Mak K, Kum CK. Early international results of laparoscopic gastrectomies. Surg Endosc. 1997;11:650-2.

26. Uyama I, Sugioka A, Fujita J, Komori Y, Matsui H, Hasumi A. Laparoscopic total gastrectomy with distal pancreatosplenectomy and D2 lymphadenectomy for advanced gastric cancer. Gastric Cancer. 1999;2:230-4.

27. Okabe H, Satoh S, Inoue H, Kondo M, Kawamura J, Nomura A, et al. Esophagojejunostomy through minilaparotomy after laparoscopic total gastrectomy. Gastric Cancer. 2007;10:176-80.

28. Kim SG, Lee YJ, Ha WS, Jung EJ, Ju YT, Jeong CY, et al. LATG with extracorporeal esophagojejunostomy: is this minimal invasive surgery for gastric cancer? J Laparoendosc Adv Surg Tech A. $2008 ; 18: 572-8$.

29. Kim HI, Cho I, Jang DS, Hyung WJ. Intracorporeal esophagojejunostomy using a circular stapler with a new purse-string suture technique during laparoscopic total gastrectomy. J Am Coll Surg. 2013;216:e11-6.

30. Du J, Shuang J, Li J, Li J, Hua J. Intracorporeal circular-stapled esophagojejunostomy after laparoscopic total gastrectomy: a novel self-pulling and holding purse-string suture technique. J Am Coll Surg. 2014;218:e67-72.

31. Usui S, Ito K, Hiranuma S, Takiguchi N, Matsumoto A, Iwai T. Hand-assisted laparoscopic esophagojejunostomy using newly developed purse-string suture instrument "Endo-PSI". Surg Laparosc Endosc Percutan Tech. 2007;17:107-10.

32. Nunobe S, Hiki N, Tanimura S, Kubota T, Kumagai K, Sano T, et al. Three-step esophagojejunal anastomosis with atraumatic anvil insertion technique after laparoscopic total gastrectomy. J Gastrointest Surg. 2011;15:1520-5.

33. Kunisaki C, Makino H, Oshima T, Fujii S, Kimura J, Takagawa $\mathrm{R}$, et al. Application of the transorally inserted anvil (OrVil) after laparoscopy-assisted total gastrectomy. Surg Endosc. 2011;25:1300-5.

34. Ito $\mathrm{H}$, Inoue $\mathrm{H}$, Odaka $\mathrm{N}$, Satodate $\mathrm{H}$, Onimaru M, Ikeda H, et al. Evaluation of the safety and efficacy of esophagojejunostomy after totally laparoscopic total gastrectomy using a trans-orally inserted anvil: a single-center comparative study. Surg Endosc. 2014;28:1929-35.

35. Uyama I, Sugioka A, Matsui H, Fujita J, Komori Y, Hatakawa Y, et al. Laparoscopic side-to-side esophagogastrostomy using a linear stapler after proximal gastrectomy. Gastric Cancer. 2001;4:98-102.

36. Kim HS, Kim BS, Lee S, Lee IS, Yook JH, Kim BS. Reconstruction of esophagojejunostomies using endoscopic linear staplers in totally laparoscopic total gastrectomy: report of 139 cases in a large-volume center. Surg Laparosc Endosc Percutan Tech. 2013;23:e209-16.

37. Ebihara Y, Okushiba S, Kawarada Y, Kitashiro S, Katoh H. Outcome of functional end-to-end esophagojejunostomy in totally laparoscopic total gastrectomy. Langenbecks Arch Surg. 2013;398:475-9.

38. Okabe H, Obama K, Tsunoda S, Tanaka E, Sakai Y. Advantage of completely laparoscopic gastrectomy with linear stapled reconstruction: a long-term follow-up study. Ann Surg. 2014;259:109-16.

39. Matsui H, Uyama I, Sugioka A, Fujita J, Komori Y, Ochiai M, et al. Linear stapling forms improved anastomoses during esophagojejunostomy after a total gastrectomy. Am J Surg. 2002;184:58-60.

40. Inaba K, Satoh S, Ishida Y, Taniguchi K, Isogaki J, Kanaya S, et al. Overlap method: novel intracorporeal esophagojejunostomy after laparoscopic total gastrectomy. J Am Coll Surg. 2010;211:e25-9.

41. Bracale U, Marzano E, Nastro P, Barone M, Cuccurullo D, Cutini $\mathrm{G}$, et al. Side-to-side esophagojejunostomy during totally laparoscopic total gastrectomy for malignant disease: a multicenter study. Surg Endosc. 2010;24:2475-9.

42. Kim HS, Kim MG, Kim BS, Yook JH, Kim BS. Totally laparoscopic total gastrectomy using endoscopic linear stapler: early experiences at one institute. J Laparoendosc Adv Surg Tech A. 2012;22:889-97.

43. Yamamoto M, Zaima M, Yamamoto H, Harada H, Kawamura J, Yamaguchi T. A modified overlap method using a linear stapler for intracorporeal esophagojejunostomy after laparoscopic total gastrectomy. Hepatogastroenterology. 2014;61:543-8.

44. Nagai E, Ohuchida K, Nakata K, Miyasaka Y, Maeyama R, Toma $\mathrm{H}$, et al. Feasibility and safety of intracorporeal esophagojejunostomy after laparoscopic total gastrectomy: inverted T-shaped anastomosis using linear staplers. Surgery. 2013;153:732-8.

45. Sakuramoto S, Kikuchi S, Futawatari N, Katada N, Moriya H, Hirai $\mathrm{K}$, et al. Laparoscopy-assisted pancreas- and spleen-preserving total gastrectomy for gastric cancer as compared with open total gastrectomy. Surg Endosc. 2009;23:2416-23.

46. Jeong O, Jung MR, Kim GY, Kim HS, Ryu SY, Park YK. Comparison of short-term surgical outcomes between laparoscopic and open total gastrectomy for gastric carcinoma: casecontrol study using propensity score matching method. J Am Coll Surg. 2013;216:184-91.

47. Bo T, Peiwu Y, Feng Q, Yongliang Z, Yan S, Yingxue H, et al. Laparoscopy-assisted vs. open total gastrectomy for advanced gastric cancer: long-term outcomes and technical aspects of a case-control study. J Gastrointest Surg. 2013;17:1202-8.

48. Wang W, Zhang X, Shen C, Zhi X, Wang B, Xu Z. Laparoscopic versus open total gastrectomy for gastric cancer: an updated meta-analysis. PLoS ONE. 2014;18(9):e88753.

49. Wang W, Li Z, Tang J, Wang M, Wang B, Xu Z. Laparoscopic versus open total gastrectomy with D2 dissection for gastric cancer: a meta-analysis. J Cancer Res Clin Oncol. 2013;139:1721-34.

50. Shen H, Shan C, Liu S, Qiu M. Laparoscopy-assisted versus open total gastrectomy for gastric cancer: a meta-analysis. J Laparoendosc Adv Surg Tech A. 2013;23:832-40.

51. Eom BW, Kim YW, Lee SE, Ryu KW, Lee JH, Yoon HM, et al. Survival and surgical outcomes after laparoscopy-assisted total gastrectomy for gastric cancer: case-control study. Surg Endosc. 2012;26:3273-81.

52. Shim JH, Oh SI, Yoo HM, Jeon HM, Park CH, Song KY. Shortterm outcomes of laparoscopic versus open total gastrectomy: a matched-cohort study. Am J Surg. 2013;206:346-51.

53. Lee JH, Ahn SH, Park DJ, Kim HH, Lee HJ, Yang HK. Laparoscopic total gastrectomy with D2 lymphadenectomy for advanced gastric cancer. World J Surg. 2012;36:2394-9.

54. Shinohara T, Kanaya S, Taniguchi K, Fujita T, Yanaga K, Uyama I. Laparoscopic total gastrectomy with D2 lymph node dissection for gastric cancer. Arch Surg. 2009;144:1138-42.

55. Usui $S$, Yoshida $T$, Ito $K$, Hiranuma $S$, Kudo SE, Iwai $T$. Laparoscopy-assisted total gastrectomy for early gastric cancer: comparison with conventional open total gastrectomy. 2005;15:309-14.

56. Kawamura H, Yokota R, Homma S, Kondo Y. Comparison of invasiveness between laparoscopy-assisted total gastrectomy and open total gastrectomy. World J Surg. 2009;33:2389-95.

57. Kim HS, Kim BS, Lee IS, Lee S, Yook JH, Kim BS. Comparison of totally laparoscopic total gastrectomy and open total gastrectomy for gastric cancer. J Laparoendosc Adv Surg Tech A. $2013 ; 23: 323-31$. 
58. Lin J, Huang C, Zheng C, Li P, Xie J, Wang J, et al. A matched cohort study of laparoscopy-assisted and open total gastrectomy for advanced proximal gastric cancer without serosa invasion. Chin Med J (Engl). 2014;127:403-7.

59. Hong L, Han Y, Jin Y, Zhang H, Zhao Q. The short-term outcome in esophagogastric junctional adenocarcinoma patients receiving total gastrectomy: laparoscopic versus open gastrectomya retrospective cohort study. Int J Surg. 2013;11:957-61.

60. Lee JH, Lee CM, Son SY, Ahn SH, Park DJ, Kim HH. Laparoscopic versus open gastrectomy for gastric cancer: long-term oncologic results. Surgery. 2014;155:154-64.

61. Shinohara T, Satoh S, Kanaya S, Ishida Y, Taniguchi K, Isogaki J. Laparoscopic versus open D2 gastrectomy for advanced gastric cancer: a retrospective cohort study. Surg Endosc. 2013;27:286-94.

62. Zuiki T, Hosoya Y, Kaneda Y, Kurashina K, Saito S, Ui T, et al. Stenosis after use of the double-stapling technique for reconstruction after laparoscopy-assisted total gastrectomy. Surg Endosc. 2013;27:3683-9.

63. Guan G, Jiang W, Chen Z, Liu X, Lu H, Zhang X. Early results of a modified splenic hilar lymphadenectomy in laparoscopy- assisted total gastrectomy for gastric cancer with stage cT1-2: a case-control study. Surg Endosc. 2013;27:1923-31.

64. Son T, Lee JH, Kim YM, Kim HI, Noh SH, Hyung WJ. Robotic spleen-preserving total gastrectomy for gastric cancer: comparison with conventional laparoscopic procedure. Surg Endosc. 2014;28:2606-15.

65. Hyun MH, Lee CH, Kwon YJ, Cho SI, Jang YJ, Kim DH, et al. Robot versus laparoscopic gastrectomy for cancer by an experienced surgeon: comparisons of surgery, complications, and surgical stress. Ann Surg Oncol. 2013;20:1258-65.

66. Kunisaki C, Makino H, Kimura J, Takagawa R, Ota M, Kosaka T, et al. Application of reduced-port laparoscopic total gastrectomy in gastric cancer preserving the pancreas and spleen. Gastric Cancer. 2014. doi:10.1007/s10120-014-0441-4.

67. Kawamura H, Tanioka T, Kuji M, Tahara M, Takahashi M. The initial experience of dual port laparoscopy-assisted total gastrectomy as a reduced port surgery for total gastrectomy. Gastric Cancer. 2013;16:602-8. 